\title{
Sinusitis and chronic cough in children
}

\author{
This article was published in the following Dove Press journal: \\ Journal of Asthma and Allergy \\ 4 July 2012 \\ Number of times this article has been viewed
}

\section{Nevin W Wilson \\ Mary Beth Hogan \\ Charles Bruce Harper \\ Kathy Peele \\ Sonia Budhecha \\ Vincent Loffredo \\ Vanessa Wong \\ University of Nevada School of Medicine, Department of Pediatrics, Section of Allergy, Immunology and Pulmonology, Reno, NV, USA}

Correspondence: Nevin W Wilson 343 Elm St, Suite 20I, Reno, NV 89503

Tel +77 57846522

Fax +7753275I73

Email nwilson@medicine.nevada.edu
Background: Chronic cough in children is a common problem, and sinusitis is a common etiology. The diagnosis of sinusitis is often clinical, but confirmation is thought to require a CT scan due to the difficulty of interpreting a Water's view sinus X-ray.

Objectives: The purposes of the study were (1) to examine the frequency of an abnormal sinus X-ray in children with a chronic cough of more than 4 weeks duration; (2) to compare the interpretation of the sinus film between allergy/pulmonary clinicians and radiologists; and (3) to correlate symptoms with X-ray results.

Methods: A chart review of 2- to 18-year-old patients with coughing exceeding 4 weeks was performed. Data was collected for patients who had received a Water's view sinus film as part of their evaluation. Exam, X-ray results, and clinical outcomes were categorized and statistical analyses performed.

Results: A total of 86 patients were included. Clinicians found that $65 \%$ of the children had positive Water's view films, compared with the radiologist's reading of $62 \%$ (non significant). Significant associations between post-tussive emesis $(P=0.01)$ and purulence $(P=0.03)$ were noted with a positive film. Positive sinus $\mathrm{X}$-ray was highly associated with all findings except wheeze when present together $(P<0.001)$.

Conclusion: Sinus abnormalities on X-ray are associated with prolonged cough in $65 \%$ of children. The Water's view sinus film is a clinically useful screening tool for clinicians in the workup of chronic cough. Certain physical findings and clinical complaints, when present concurrently, correlate with the X-ray results.

Keywords: Water's view sinus X-ray, asthma, allergic rhinitis, radiologist, post-tussive emesis, wheezing

\section{Introduction}

Chronic cough is a common presenting symptom in a pediatric practice. Correctly determining the etiology of prolonged cough in children is important to treatment success. ${ }^{1}$ History and clinical findings alone are often insufficient to determine the cause. The timing and character of cough are sometimes poor indicators of the actual diagnosis. Frequent underlying etiologies of chronic cough are asthma, bronchitis, allergic rhinitis, sinusitis, gastroesophageal reflux, and postviral cough. ${ }^{2}$ Less common pediatric cough disorders include examples such as tic disorders and cilia dyskinesia. ${ }^{3,4}$

The association between chronic cough and sinusitis in children is well known. ${ }^{5}$ Purulent rhinorrhea, sneezing, and postnasal drip secondary to sinusitis often lead to chronic cough. Short antibiotic treatment courses are commonly prescribed for presumed clinical sinusitis. ${ }^{1,5}$ This presumption may not be accurate, as viral infections 
and allergic rhinitis also cause cough with purulence. Subacute or chronic sinusitis is sometimes not considered when the cough has persisted for longer than 4 weeks. The diagnosis is frequently missed because it is assumed that an initial treatment of 10 days of antibiotics is adequate to treat the sinusitis. Chronic sinusitis may require an extended antibiotic course, and repetitive short courses may lead to bacterial resistance..$^{6,7}$

Noninvasive studies, such as chest radiographs, pulmonary function testing, and sinus computed tomography (CT) scans are frequently used tools in the evaluation of chronic cough. ${ }^{8,9}$ Ultimately, bronchoscopy may be required to determine the correct etiology in some patients. However, while studies requiring sedation, such as a CT scan or bronchoscopy, may be useful in determining the etiology of the cough, they can be difficult for clinicians to arrange in an outpatient pediatric setting, particularly for young children.

The primary purpose of this study was to examine the frequency of abnormal Water's view sinus X-rays in children with a chronic cough of more than 4 weeks duration. The second purpose of the study was to evaluate the practicality of this outpatient study by comparing the difference in interpretation of the Water's view sinus X-ray between allergy/pulmonary clinicians and radiologists. The third purpose of the study was to correlate concurrent symptoms associated with the chronic cough, such as posttussive emesis, postnasal drip, and purulent rhinorrhea, with X-ray results.

\section{Methods}

\section{Inclusion and exclusion criteria}

Researchers reviewed 110 pediatric charts between June 2009 and June 2010. All had a chief complaint of persistent cough for a minimum of 4 weeks. Ages ranged from 2 to 18 years. All patients were seen in a pediatric allergy/pulmonary practice with a regional referral population base of about 500,000. Chronic cough was defined as 4 weeks duration based on American Lung Association guidelines. ${ }^{9}$ Symptoms and exam findings were based on data recorded in the chart at the time of the initial visit. All included patients had received a Water's view sinus X-ray film as part of their evaluation. All films had been independently reviewed by the ordering physician (NWW, MBH, and SB) and a radiologist. Excluded patients were those who did not receive a Water's view sinus film; those with incomplete data; those with a cough lasting less than 4 weeks; those younger than 2 years of age; and those without a clinician/radiologist comparison. The study was institutional review board-exempt per institutional guidelines. No unique patient identifiers were used.

\section{Water's view radiologic technique}

A Water's view X-ray is a view obtained from the chin, exposing the maxillary sinuses. Clinician reading or radiologist dictation of mucosal thickening of more than $6 \mathrm{~mm}$, unilateral or bilateral opacification, or presence of an air-fluid level was classified as abnormal. The patients were categorized according to their history, physical exam, sinus film results, and clinical outcomes.

\section{Statistical analysis}

Statistical analysis was performed through Fisher's exact and Chi-squared tests, using a GraphPad InStat software (GraphPad Software Inc, La Jolla, CA).

\section{Results}

A total of 110 charts were reviewed. Of these, 24 were excluded due to incomplete data or cough less than 4 weeks. The remaining 86 patients, who experienced chronic cough of at least 4 weeks duration and had a Water's view sinus $\mathrm{X}$-ray as part of their diagnostic workups, were included. Mean age of the included population was 5.6 years, and mean duration of cough was 13.9 weeks. A large portion of the patient population had previously been diagnosed with asthma (73\%), and 51\% had demonstrated allergic sensitization with positive allergy skin tests. Demographic data is listed in Table 1.

Clinicians interpreted 56 of 86 Water's view films $(65 \%)$ as indicative of sinusitis. Of the 56 positive films, significant disease was identified in the maxillary sinuses. Two had maxillary air-fluid levels, and 33 (59\%) children with chronic cough had complete opacification of at least one maxillary sinus. Independent evaluation of these films by radiologists resulted in their interpretation of $62 \%$ as abnormal. There was no significant statistical difference (Chi square) between the clinician's interpretation of the Water's view films and the radiologist's report. Results are listed in Table 2.

Table I Demographic data of patients

\begin{tabular}{lll}
\hline Number of patients enrolled & 86 & \\
Mean age & 5.6 years & Range 2-18 \\
No 2-5 years of age & $5 \mathrm{I}$ & $59 \%$ \\
No male & 50 & $58 \%$ \\
No female & 36 & $42 \%$ \\
Mean duration of cough & 13.9 weeks & \\
No with previous diagnosis of asthma & $6 \mathrm{I}$ & $71 \%$ \\
No with positive allergy skin tests & 44 & $51 \%$ \\
\hline
\end{tabular}


Table 2 Comparison of $X$-ray readings from clinicians and radiologists

\begin{tabular}{llll}
\hline & Positive X-ray & Negative X-ray & Percent positive \\
\hline Clinician & 56 & 30 & 65 \\
Radiologist & 53 & 33 & 62 \\
\hline
\end{tabular}

Table 3 Outcomes of cough

\begin{tabular}{|c|c|c|c|c|c|}
\hline & $\begin{array}{l}\text { Resolution of cough with } \\
\text { treatment }\end{array}$ & Persistent cough & & Referral to ENT & \\
\hline \multirow{2}{*}{$\begin{array}{l}\text { Patients with } \\
\text { positive films }(N=56)\end{array}$} & $46(82 \%)$ & 8 & & 2 & \\
\hline & Treated for asthma & $\begin{array}{l}\text { Treated for } \\
\text { rhinitis }\end{array}$ & $\begin{array}{l}\text { Resolved without } \\
\text { treament }\end{array}$ & Diagnosed with tic cough & Treated for GERD \\
\hline $\begin{array}{l}\text { Patients with negative } \\
\text { films }(N=30)\end{array}$ & 13 & 7 & 6 & 2 & 2 \\
\hline
\end{tabular}

Note: $P>0.05$.

Abbreviations: ENT, ear nose and throat surgeon; GERD, gastroesophageal reflux disease.

Of the 56 patients with initial positive films, all were placed on a minimum of a 2-week course of antibiotics, and 46 had resolution of their cough (82\%). One missed a followup appointment, and it was unknown if the cough resolved. Eight patients had persistent cough and sinusitis, and 2 were sent to an otolaryngologist for consultation Outcomes are listed in Table 3.

For the 30 patients $(35 \%)$ with negative initial sinus $\mathrm{X}$-rays, 13 were treated for asthma with albuterol, montelukast, inhaled steroids, or combination therapy. All had resolution of their cough. Seven children were treated with topical nasal steroids for rhinitis, with resolution of their cough. Two patients were diagnosed with a tic cough, and two were treated for gastroesophageal reflux disease. Two patients presenting with chronic cough who were on antibiotics prescribed by their primary-care physicians had the antibiotics discontinued upon obtaining a negative sinus film.

Significant associations were found for exam findings of purulent rhinorrhea $(P=0.01)$ and inflamed nasal mucosa $(P=0.01)$, but not for wheezing on exam. Complaints of post-tussive emesis $(P=0.01)$, postnasal drip $(P=0.05)$, and purulent rhinorrhea $(P=0.02)$ correlated with positive interpretation of the sinus film. Worsening cough at night and with exercise did not correlate. Seventeen of 20 patients with concurrent symptoms of post-tussive emesis, purulent nasal discharge, and postnasal drip had a positive sinus $\mathrm{X}$-ray $(P<0.001)$. Comparison of sinus $\mathrm{X}$-ray results with exam findings and symptoms is listed in Table 4.

Table 4 Distribution of specific symptoms of patients

\begin{tabular}{|c|c|c|c|c|c|c|}
\hline & $\begin{array}{l}\text { Symptom } \\
\text { positive and } \\
\text { positive film }\end{array}$ & $\begin{array}{l}\text { Symptom } \\
\text { positive and } \\
\text { negative film }\end{array}$ & $\begin{array}{l}\text { Percent with positive } \\
\text { sinus film and positive } \\
\text { symptom }\end{array}$ & $\begin{array}{l}\text { P value } \\
\text { (Fisher's } \\
\text { exact test) }\end{array}$ & $\begin{array}{l}\text { Symptom } \\
\text { negative and } \\
\text { negative film }\end{array}$ & $\begin{array}{l}\text { Symptom } \\
\text { negative and } \\
\text { positive film }\end{array}$ \\
\hline \multicolumn{7}{|l|}{ Exam findings } \\
\hline Wheezing on exam & 9 & 27 & $75 \%$ & 0.5 & 3 & 47 \\
\hline Purulent rhinorrhea & 19 & 30 & $86 \%$ & 0.01 & 3 & 37 \\
\hline Inflamed mucosa & 48 & 13 & $73 \%$ & 0.01 & 17 & 8 \\
\hline \multicolumn{7}{|l|}{ Symptoms } \\
\hline Cough worse at night & 52 & 3 & $65 \%$ & $>0.05$ & 27 & 4 \\
\hline Cough worse with exercise & 25 & 16 & $64 \%$ & $>0.05$ & 14 & 31 \\
\hline Post-tussive emesis & 33 & 25 & $49 \%$ & 0.01 & 8 & 5 \\
\hline Postnasal drip & 43 & 17 & $72 \%$ & 0.05 & 17 & 12 \\
\hline Purulent rhinorrhea & 46 & & $82 \%$ & 0.02 & 17 & 10 \\
\hline History of wheezing & 40 & 11 & $69 \%$ & $>0.05$ & 18 & 14 \\
\hline Asthma diagnosis & 38 & 9 & $68 \%$ & $>0.05$ & 21 & 17 \\
\hline $\begin{array}{l}\text { Post-tussive emesis, postnasal } \\
\text { drip, and purulent rhinorrhea }\end{array}$ & 17 & 27 & $85 \%$ & 0.04 & 3 & 39 \\
\hline
\end{tabular}




\section{Discussion}

Because chronic cough may be the result of multiple diseases, the establishment of an accurate differential diagnosis is necessary for successful treatment. The ability of clinicians to link chronic cough to sinusitis has been limited by the lack of practical research studies concerning the accuracy of sinus imaging techniques combined with achieving the lowest possible risk to the patients. In our study, the Water's view sinus film was shown to be a quick, reliable method for diagnosing sinusitis in children with chronic cough. Clinician accuracy was similar to the radiologists' interpretation, even in children younger than 5 years of age. Ultimately, $65 \%$ of children with sinusitis on X-ray were treated until cough resolution or referral. For the $35 \%$ without sinusitis, treatment of other causes of cough led to eventual resolution (Table 3).

Some children with chronic wet cough based on cultures obtained at bronchoscopy may have bacterial bronchitis as an etiology. This is particularly true for those children who have chronic wet cough and bronchiectasis. ${ }^{10}$ Our referral group has both allergy/immunology and pulmonary specialty boards represented and has developed a clinically useful evaluative pathway for cough lasting longer than 4 weeks. This includes pulmonary function testing with and without treadmill, bronchodilator response testing, allergy evaluation, chest and/ or sinus X-rays as initial noninvasive testing. The order in which studies are obtained is frequently dictated by clinical presentation, including whether the cough is described as wet or dry. We have found bronchoscopy to be an extremely helpful tool if invasive tools are required to determine the etiology of chronic cough. Studies of populations in which allergy status has not yet been defined suggest that bacterial bronchitis found at bronchoscopy may be an etiologic problem. ${ }^{11,12}$ The nature of the underlying population (atopic vs nonatopic) assists in determining the next step of the diagnostic evaluation. Our population is largely atopic (Table 1) and our data regarding rhinosinusitis as a cause of cough are consistent with other specific allergic populations. ${ }^{13,14}$

Without question, the best technique to evaluate sinus pathology is the CT scan or magnetic resonance imaging scan, and there are clearly limitations to using the Water's view. ${ }^{15,16}$ However, the Water's view may continue to be useful for the initial evaluation of chronic cough in children for the time being. First, it is relatively inexpensive and still available at even the most rural hospitals. Second, the Water's view does not require sedation, a significant issue when the child is younger than 4 or 5 years of age. In addition, obtaining a limited sinus CT scan as opposed to a full CT scan is problematic in many hospitals due to reimbursement issues. Third, the Water's view film requires less radiation than the limited sinus CT scan, although it is possible to lower the dose of radiation during a limited sinus $\mathrm{CT}$ and still obtain adequate images. ${ }^{17}$ The MiniCAT ${ }^{\circledR}$, a compact upright computed tomography system allowing immediate visualization of the sinuses, is a new technique that bypasses most of these issues. When the MiniCAT becomes more readily available to all ordering physicians, the Water's view will most likely become obsolete.

The primary concerns voiced in clinical studies of sinusitis involve the limitations of the Water's view film in determining the presence of significant anatomic abnormalities or occlusion of the osteomeatal complex. For chronic cough not responding to appropriate management, a sinus $\mathrm{CT}$ is of great value in determining both sinusitis and anatomic abnormalities. Tatli et al ${ }^{18}$ examined 42 children with chronic cough, ranging from 3 to 16 years of age. Using a paranasal sinus limited CT, they found sinus abnormalities in $66.6 \%$. They concluded that sinus abnormalities are common among pediatric patients with chronic cough, and imaging studies of the sinuses should be considered.

The real value of the Water's view technique is not in the evaluation of the anatomic cause of sinusitis, however, but as a quick, practical technique for determining the presence or absence of sinusitis as a cause for pediatric chronic cough. This screening tool utilizes less radiation than a CT scan and avoids the need for sedation. Garcia et a ${ }^{19}$ compared radiographs and CT scans for the examination of the paranasal sinuses of 91 children from 2 to 17 years who had chronic upper-respiratory tract symptoms for at least 3 months. They found that $63 \%$ had chronic sinusitis, and the severity of disease on plain film correlated with CT scan findings. Forty-four percent of the patients had pansinusitis. When sinus radiographs were compared with CT scans ( $n=70$ cases), only those radiographs demonstrating minimal disease had false negative readings. The sensitivity and specificity for a Water's view to confirm clinically significant chronic sinusitis were acceptable at $76 \%$ and $81 \%$, respectively. Garcia et a ${ }^{19}$ concluded that a single Water's view film is an acceptable part of the initial evaluation of pediatric chronic sinusitis.

In our practice, we chose a single view of the maxillary sinuses as our screening study to limit radiation exposure compared with the standard sinus series. Williams et $\mathrm{al}^{20}$ found that the agreement between a Water's view and the four-view sinus series was substantial for the maxillary sinuses. Ros, Herman and Azar-Kia ${ }^{21}$ examined the utility 
of the Water's view in the diagnosis of acute sinusitis in children. The interpretation of the Water's view alone was compared with that of a three-view (anterior/posterior, lateral, Water's) series. The overall accuracy of the Water's view in diagnosing childhood acute sinusitis was $87 \%$. They concluded that the Water's view is a sufficient study in the evaluation of suspected acute sinusitis in children.

Probably the most commonly discussed issue concerning the Water's view involves the false positive rate in young children. A frequently cited article by Kovatch et a ${ }^{22}$ identified the incidence of abnormal maxillary sinus radiographs in a group of unselected children. These children had skull radiographs performed for indications unrelated to the presence of a respiratory infection. They found that in subjects younger than 1 year of age, abnormal maxillary sinus radiographs were common, irrespective of respiratory symptoms and signs. However, in children older than 1 year of age, abnormal maxillary sinus radiographs were infrequent. Crying alone was not associated with abnormal radiographs in the older age group. Because of this study, it has been our practice to limit the screening Water's view to children 24 months of age and older to minimize the possible false positives associated with age-related concerns at or under 1 year of age.

Etiologies causing pediatric sinus disease may differ from adult sinusitis. Yang et $\mathrm{al}^{23}$ obtained CT scans on 53 children ages 2 to 13 years with chronic cough and found that 43 had sinusitis. All were treated with antibiotics for 6 to 8 weeks. After treatment, $81.4 \%$ of patients were fully recovered and the remaining $18.6 \%$ were significantly improved. A recent publication suggests that, unlike adults, children may have aerobic bacteria present in chronically infected sinuses. ${ }^{24}$ In this study, more than $70 \%$ of children had aerobic bacteria present in their sinuses. Researchers found alpha-hemolytic streptococci (20.8\%), Hemophilus influenzae (19.5\%), Streptococcus pneumoniae (14.0\%), coagulase-negative staphylococci (13.0\%), and Staphylococcus aureus $(9.3 \%)$ at the time of surgery.

This fundamental difference from adults, with $70 \%$ of children having bacterial chronic sinusitis, suggests that treating children with a more prolonged, 2- to 3-week course of an antibiotic is a valid therapeutic option. A follow-up evaluation is frequently performed, as a large number of these referred children have previously failed short courses ( $<10$ days) of antibiotics. One reason to choose to perform a pediatric Water's view is to influence the decision concerning whether a long course of antibiotics is required, particularly if previous short courses have failed. This concern for appropriately establishing the need for longer antibiotic courses is also supported by our data, which revealed that $35 \%$ needed a therapy other than antibiotics.

Our population was notable for its high degree of atopy and asthma. The combined presence of these diseases increased the degree of complexity in determining the origin of the cough. Ueda and Yoto ${ }^{25}$ evaluated both allergic (skintest positive) and nonallergic children with chronic respiratory symptoms. Radiographs revealed sinusitis in 135 patients $(92.5 \%)$ with allergic disease. Our data also revealed a high rate of sinus disease in those with evidence of atopy. This suggests that atopy is a risk factor for development of chronic sinusitis in children.

One of the questions addressed by this study was whether symptoms occurring alone or in combination were associated with an abnormal sinus X-ray. Nguyen et $\mathrm{al}^{26}$ examined the prevalence of chronic sinusitis among children who presented to allergy clinics with chronic ( $\geq 3$ months) respiratory symptoms. Using a CT evaluation, 63 percent were found to have chronic sinusitis. The combination of moderate to severe rhinorrhea and cough with minimum sneezing had a specificity of $95 \%$ and a sensitivity of $38 \%$ in predicting the presence of chronic sinusitis. We also found that symptoms of purulent rhinorrhea, postnasal drip, and inflamed mucosa were associated with the presence of sinusitis on X-ray (Table 4). The clinical accumulation of at least three symptoms was more reflective of a positive film indicating sinusitis. However, the infrequency of this symptom triad suggests that screening for sinusitis with a Water's view sinus X-ray is still a necessary component of the evaluation of children with a cough lasting longer than 4 weeks.

In conclusion, we have demonstrated that $65 \%$ of children with a cough lasting more than 1 month had an abnormal Water's view sinus X-ray. The Water's view is a useful screening tool in this particular clinical situation. Symptoms of purulent rhinorrhea, post-tussive emesis, and postnasal drip were associated with an abnormal sinus X-ray, particularly if the three symptoms were concurrent. This suggests that when all three symptoms are present, radiological confirmation may not be necessary. Most importantly to clinical practice, we found that allergy/pulmonary clinicians are capable of accurately reading Water's view sinus films to provide immediate, realtime diagnosis and treatment options for chronic cough.

\section{Disclosure}

The authors have no conflicts of interest to disclose. Presented in part at the meeting of the American College of Allergy, Asthma, and Immunology, November 2010. 


\section{References}

1. Morice AH, Fontana GA, Sovijarvi AR, et al. The diagnosis and management of chronic cough. Eur Respir J. 2004;24:481-492.

2. Khoshoo V, Edell D, Mohnot S, Haydel R Jr, Saturno E, Kobernick A. Associated factors in children with chronic cough. Chest. 2009;136: 811-815.

3. Welch JE, Hogan MB, Wilson NW. Ten-year experience using a plastic, disposable curette for the diagnosis of primary ciliary dyskinesia. Ann Allergy Asthma Immunol. 2004;93:189-192.

4. Hogan MB, Wilson NW. Tourette's syndrome mimicking asthma. J Asthma. 1999;36(3):253-256.

5. Barbi E, Longo G. Chronic and recurrent cough, sinusitis and asthma. Much ado about nothing. Pediatr Allergy Immunol. 2007;18 Suppl 18: 22-24.

6. Yun DJ, Hong CH, Oh KK. Chronic cough and sinusitis in children - the role of antimicrobials. Yonsei Med J. 1983;24(1):67-75.

7. Zuckerman IH, Perencevich EN, Harris AD. Concurrent acute illness and comorbid conditions poorly predict antibiotic use in upper respiratory tract infections: a cross-sectional analysis. BMC Infect Dis. 30, 2007;7:47.

8. Ramadan HH. Pediatric sinusitis: update. J Otolaryngol. 2005;34 Suppl 1: S14-S17.

9. Chang AB. Chronic non-specific cough in children. Paediatr Child Health. 2008;18(7):333-339.

10. Chang AB, Redding GJ, Everard ML. Chronic wet cough, chronic suppurative lung disease and bronchiectasis. Pediatr Pulmonol. 2008;43(6):519-531.

11. Marchant JM, Masters IB, Taylor SM, Cox NC, Seymour GJ, Chang AB. Evaluation and outcome of young children with chronic cough. Chest. 2006;129(5):1132-1141.

12. Zgherea D, Pagala S, Mendiratta M, Marcus MG, Shelov SP, Kazachkov M. Bronchoscopic findings in children with chronic wet cough. Pediatrics. 2012;129(2):e364-e369.

13. Lin SW, Wang YH, Lee MY, et al. Clinical spectrum of acute rhinosinusitis among atopic and nonatopic children in Taiwan. Int $J$ Pediatr Otorhinolaryngol. 2012;76(1):70-75.

14. Ogershok PR, Warner DJ, Hogan MB, Wilson NW. Prevalence of pollen sensitization in younger children who have asthma. Allergy Asthma Proc. 2007;28:654-658.
15. Leo G, Triulzi F, Incorvaia C. Sinus imaging for diagnosis of chronic rhinosinusitis. Curr Allergy Asthma Rep. 2012;12:136-143.

16. White PS, Robinson JM, Stewart IA, Doyle T. Computerized tomography mini-series: an alternative to standard paranasal sinus radiographs. Aust N Z J Surg. 1990;60:25-29.

17. Mulkens TH, Broers C, Fieuws S, Termote JL, Bellnick P. Comparison of effective doses for low-dose MDCT and radiographic examination of sinuses in children. AJR Am J Roentgenol. 2005;184(5):1611-1618.

18. Tatli MM, San I, Karaoglanoglu M. Paranasal sinus computed tomographic findings of children with chronic cough. Int $J$ Pediatr Otorhinolaryngol. 2001;60(3):213-217.

19. Garcia DP, Corbett ML, Eberly SM, et al. Radiographic imaging studies in pediatric chronic sinusitis. JAllergy Clin Immunol. 1994;94: 523-530.

20. Williams JW, Roberts L, Distell B, et al. Diagnosing sinusitis by X-ray: is a single Waters view adequate? J Gen Intern Med. 1992;7(5): 481-485.

21. Ros SP, Herman BE, Azar-Kia B. Acute sinusitis in children: is the Water's view sufficient? Pediatr Radiol. 1995;25(4):306-307.

22. Kovatch AL, Wald ER, Ledesma-Medina J, Chiponis DM, Bedingfield B. Maxillary sinus radiographs in children with nonrespiratory complaints. Pediatrics. 1984;73(3):306-308.

23. Yang L, Tang D, Duan C, et al. The character of pediatric chronic sinusitis with chronic cough. Lin Chung Er Bi Yan Hou Tou Jing Wai Ke Za Zhi. 2007;21(17):779-781.

24. Hsin CH, Su MC, Tsao CH, Chuang CY, Liu CM. Bacteriology and antimicrobial susceptibility of pediatric chronic rhinosinusitis: a 6-year result of maxillary sinus punctures. Am J Otolaryngol. 2010; 31(3):145-149.

25. Ueda D, Yoto Y. The ten-day mark as a practical diagnostic approach for acute paranasal sinusitis in children. Pediatr Inf Dis J. 1996; 15(7):576-579.

26. Nguyen KL, Corbett ML, Garcia DP, et al. Chronic sinusitis among pediatric patients with chronic respiratory complaints. J Allergy Clin Immunol. 1993;92(6):824-830.
Journal of Asthma and Allergy

\section{Publish your work in this journal}

The Journal of Asthma and Allergy is an international, peer-reviewed open-access journal publishing original research, reports, editorials and commentaries on the following topics: Asthma; Pulmonary physiology; Asthma related clinical health; Clinical immunology and the immunological basis of disease; Pharmacological interventions and

\section{Dovepress}

new therapies. Issues of patient safety and quality of care will also be considered. The manuscript management system is completely online and includes a very quick and fair peer-review system, which is all easy to use. Visit http://www.dovepress.com/testimonials.php to read real quotes from published authors. 